\title{
El Fuego Nuevo: interpretación de una « ofrenda contada » tlapaneca (Guerrero, México)
}

Danièle Dehouve

\section{(2) OpenEdition \\ 1 Journals}

Edición electrónica

URL: http://journals.openedition.org/jsa/1996

DOI: $10.4000 /$ jsa.1996

ISSN: 1957-7842

Editor

Société des américanistes

Edición impresa

Fecha de publicación: 1 enero 2001

Paginación: 89-112

ISSN: 0037-9174

\section{Referencia electrónica}

Danièle Dehouve, «El Fuego Nuevo: interpretación de una « ofrenda contada » tlapaneca (Guerrero, México) », Journal de la société des américanistes [En línea], 87 | 2001, Publicado el 17 noviembre 2005, consultado el 19 abril 2019. URL : http://journals.openedition.org/jsa/1996 ; DOI : 10.4000/jsa.1996 


\title{
EL FUEGO NUEVO :
}

\section{INTERPRETACIÓN DE UNA « OFRENDA CONTADA » TLAPANECA (GUERRERO, MÉXICO)}

\author{
Danièle DEHOUVE *
}

\begin{abstract}
Aunque la primera descripción de las ofrendas contadas tlapanecas fue realizada en 1930, y que en los años sesenta, Karl Nowotny señaló la relación que tenían con ciertas imágenes de unos códices del Grupo Borgia, desde aquella fecha se han registrado pocos avances en las interpretaciones. Este artículo presenta los primeros resultados de una investigación en curso en varias comunidades de un municipio tlapaneco. Compara una ofrenda al Fuego realizada en dos pueblos, de modo que surja, allende las variantes, la estructura de la ofrenda vegetal compuesta de tres niveles, así como la concepción y la simbólica de los números sagrados.
\end{abstract}

Palabras claves : Ofrendas contadas, simbólica de los números, tlapanecos, códices del Grupo Borgia.

\section{Le Feu Nouveau : interprétation d'une " offrande comptée " tlapanèque (Guerrero, Mexique)}

Bien que la première description des offrandes comptées tlapanèques date de 1930 et que, dans les années soixante, Karl Nowotny ait signalé l'existence d'une parenté entre celles-ci et certaines images des codex du Groupe Borgia, les interprétations des séquences numériques ont peu progressé depuis. Cet article présente les premiers résultats d'une recherche en cours dans plusieurs communautés d'une municipalité tlapanèque. Elle compare une offrande au Feu réalisée dans deux villages, de façon à faire apparaître, par-delà les variantes, la structure de l'offrande végétale composée de trois niveaux, ainsi que la conception et la symbolique des nombres sacrés.

MOTS CLÉS: Offrandes comptées, symbolique des nombres, Tlapanèques, codex du Groupe Borgia.

New Fire: Interpretation of a mumerical offering by the Tlapanecs (Guerrero, Mexico)

The first description of Tlapanec numerical offerings dates from 1930 and Karl Nowotny showed the relation between them and some images belonging to the Borgia Group codex.

* Laboratoire d'ethnologie et de sociologie comparative, UMR 7535 du CNRS, Maison de l'archéologie et de l'ethnologie, 21, allée de l'Université 92023 Nanterre cedex.

Journal de la Société des Américanistes, 2001, 87 : p. 89 à 112. Copyright (C) Société des Américanistes. 
However, since that date, the interpretations have not progressed notably. This article presents the first results of an ongoing research in various communities of a Tlapanec municipality. It compares an offering to Fire performed in two villages, in order to bring to light, beyond surface variations, its three level structure and the native conception of sacred symbolical numbers.

KEY wORDS : Numerical offerings, symbolical numbers, Tlapanecs, codex of the Borgia Group.

Las civilizaciones mesoamericanas han basado una gran parte de su organización social y de su religión en una ciencia de los números. Sin embargo, los investigadores no han estudiado el uso de la aritmética en todos sus campos de aplicación, sino que han privilegiado algunos como, por ejemplo, los computos calendáricos. Pensamos que otro centro de interés sería el de las « of rendas contadas », es decir, la costumbre de presentar ofrendas constituidas de varios objetos en números cuidadosamente contados.

La primera descripción de los rituales con ofiendas contadas fue realizada entre los indígenas de habla tlapaneca por el geógrafo Leonhardt Schultze Jena quien viajó por la Montaña de Guerrero en los años treinta ${ }^{2}$. Varias décadas después, dos antropólogos, Marion Oettinger y Peter van der Loo, hicieron a su vez varias descripciones de rituales tlapanecos ${ }^{3}$. Mientras tanto, se registraba la existencia de costumbres semejantes en otros grupos indígenas de México, como los chontales y mixes del estado de Oaxaca ${ }^{4}$. Así se diseñaba un área geográfica incluyendo los estados de Guerrero y Oaxaca, que puede aparecer como un foco cultural (o uno de los focos culturales) de las ofrendas contadas.

Varios códices del llamado Grupo Borgia (Fejérváry-Mayer, Laudy Cospi) presentan series numéricas. Aunque no se conozca exactamente su procedencia, se puede pensar que fue alguna región del centro de México. El hecho es que su contenido quedó mucho tiempo sin explicación. En los años sesenta, Karl Nowotny, apoyándose en las descripciones de rituales tlapanecos actuales realizadas por Schultze Jena, pudo demostrar que las series numéricas de los códices representan ofrendas contadas destinadas a unas deidades precortesianas ${ }^{6}$. Sin embargo, desde aquella fecha, se han registrado pocos avances en las interpretaciones y todavía no disponemos de una teoría general del papel desempeñado por la numeración de los objetos ofrendados.

Para progresar en este camino, propongo un método de análisis de las ofrendas contadas que consiste en :

1. No buscar el significado de los números en sí mismos, sino ubicándolos en el marco de una teoría de la ofrenda. En otros términos y como se va a explicar a continuación, pienso que es imposible dar razón del uso de los números si no se logra entender lo que es una ofrenda y cuáles son sus varios estratos o niveles.

2. No satisfacerse de la descripción de una ofrenda dada en un pueblo dado. Una observación de este tipo es incapaz de desembocar en un modelo de la ofrenda, el cual sólo se puede deducir de una comparación entre varios lugares. El método de análisis que tengo la intención de proseguir durante varios años consiste en comparar las mismas ofrendas en varios pueblos distintos. En este artículo presento un primer resultado que se desprende de la comparación de una sola ofrenda en dos pueblos distintos. 
Espero así llegar a proponer un modelo interpretativo de las ofrendas y del uso de los números en ellas para confrontarlo con otras descripciones realizadas en las regiones indígenas de México.

\section{LOS RITUALES DE CAMBIO DE LAS AUTORIDADES Y AÑO NUEVO}

La ofrenda que voy a presentar pertenece a un conjunto de rituales realizados a principios de enero en ocasión del cambio anual de las autoridades municipales de nivel subalterno. En efecto, un municipio contiene dos niveles de administración. El ayuntamiento municipal encabezado por un presidente municipal, electo por tres años, tiene su sede en un pueblo mayor que sirve de cabecera. Los pueblos subalternos, que en la región tlapaneca de Guerrero, llegan a un número de 50 a 100 por municipio, acostumbran elegir anualmente sus autoridades encabezadas por un « comisario municipal ». Después de recibir las insignias de su poder (sellos y bastones de mando) de manos del presidente municipal, las autoridades de los pueblos subalternos realizan una serie de ritos que se extienden durante una semana y comprenden numerosas ofrendas contadas.

Anteriormente existían tres municipios tlapanecos, de este a oeste : Malinaltepec, Tlacoapa y Zapotitlán Tablas. Los rituales de sólo los dos primeros han sido objeto de descripciones : Malinaltepec por Leonhardt Schultze Jena en los años treinta y Peter van der Loo en los ochenta, Tlacoapa por Marion Oettinger en los setenta. En lo que se refiere a Malinaltepec, no tenemos ninguna noticia de la existencia histórica de rituales de cambio de comisarios del tipo que nos interesa. Sin embargo, Marion Oettinger recuerda una fiesta celebrada en Tlacoapa por un cuerpo municipal llamado " inspectores » que desapareció en 1960. Aunque este autor no diga en qué momento del año se verificaba el ritual, pienso que estaba relacionado con los del mes de enero:

«[...] Los inspectores celebraban una fiesta del tipo mayordomía. Veneraban una imagen llamada iy a wha (agua que brota) en lengua tlapaneca, que no tiene ningún equivalente católico o español [...] Cuando en 1960 llegaron los sacerdotes de la Misión, se espantaron al ver este tipo de culto y en cuanto se recobraron de la sorpresa, prohibieron la veneración de este « santo » del inspector y trasładaron la imagen a la ciudad de México » (Oettinger 1980, p. 139).

El tercer municipio tlapaneco, Zapotitlán Tablas, no fue el objeto de ninguna monografía etnográfica. Cuando lo visité entre 1974 y 1976, me enteré que se realizaban aún los rituales de cambios de autoridades municipales que habían sido señalados por uno de sus sacerdotes: el cura de la parroquia de Atlixtac que mencionó la particularidad de Teocuitlapa (que perteneció mucho tiempo al municipio de Zapotitlán Tablas) « donde, cada año bañan al comisario entrante a media noche con todos sus regidores, para que tengan buena suerte » (Catedral 1953, p. 51).

En 1993, el municipio de Zapotitlán Tablas se separó en dos : la parte septentrional conservó el nombre de su cabecera, y la parte meridional, encabezada por el pueblo de Acatepec, se volvió un municipio independiente. Los rituales de cambio de autoridades permanecen vigentes en ambas partes hasta la actualidad. Los pueblos donde los estudio pertenecen al nuevo municipio de Acatepec.

Hay que hacer notar que la existencia de rituales semejantes ha sido señalada en otras regiones indígenas de México, como entre los mixes de Oaxaca, a propósito de 
los cuales Frank Lipp señala el baño ritual de las autoridades en Atlixco y describe el ritual de año nuevo que se celebró por última vez en 1970 en Ixcatlán (Lipp 1991, pp. 140-146).

Para mi propósito, los rituales de enero presentan un interés excepcional, en primer lugar porque son comunales y, por lo tanto, realizados al mismo tiempo en muchos pueblos donde se pueden observar y comparar. Los dos municipios de Zapotitlán Tablas y Acatepec tienen un número aproximado de cien localidades; un estudio de su historia permite reconstruir el poblamiento de la sierra y trazar la filiación entre las comunidades. Aparece de este modo cuáles pueblos son los más antiguos y cuáles se han fundado a partir de mediados del siglo XIx. Tengo la intención, en el futuro, de deducir un proceso de «divergencia » ritual de dicho proceso de segmentación poblacional ${ }^{7}$.

Por el momento, quiero proporcionar unos resultados de las observaciones realizadas en el pueblo de Tres Cruces (al sur del municipio de Acatepec) en enero de 2000, y en el pueblo de Apetzuca (al norte del mismo municipio) en enero de 2001. En ambas localidades, los rituales se prolongan durante una semana y culminan una noche de viernes a sábado, durante la cual las ofrendas contadas son presentadas simultáneamente en varios puntos sagrados de la periferia del territorio comunal. La misma noche, las autoridades municipales se bañan en un ojo de agua para realizar una purificación ritual, antes de entrar solemnemente en el local municipal para tomar posesión oficialmente de su cargo. Los responsables civiles tienen la obligación de guardar una « dieta », es decir, comer comida preparada sin condimentos y, según el lugar, observar una abstinencia sexual durante un periodo de una semana a tres meses. En el transcurso de la semana ritual, todavía no tienen el derecho de hacer justicia ni mandar a los policías, de tal forma que el pueblo queda sin autoridad formal. El objetivo de los rituales públicos, además de otorgar una legitimación al poder político, es « pedir el año », es decir, la vida de cada uno de los habitantes del pueblo, de lo que se encargan las autoridades civiles. Un error en la confección de las ofrendas o una ruptura de la abstinencia sexual por parte de uno de los hombres en puesto pueda provocar la muerte de los vecinos del lugar ${ }^{8}$.

Los oficiantes principales de estos rituales son, pues, las autoridades municipales de los pueblos subalternos del municipio. En Tres Cruces (900 habitantes) los responsables civiles anuales son unos cuarenta hombres, más o menos lo mismo que en Apetzuca ( 600 habitantes). A su lado intervienen unos ancianos llamados xiña (abuelito) que ayudan a elaborar las ofrendas, las sahuman con copal y se reparten los puntos sagrados donde se depositan durante la última noche de la semana. Todos se encuentran bajo el mando de un xiña xuahi (abuelito del pueblo) que puede recibir la ayuda de otro hombre, generalmente un poco más joven. Estos dos ancianos son los especialistas religiosos encargados años tras años de encabezar los rituales, es decir; decidir del número de los objetos contados en las ofrendas y del número de los puntos sagrados venerados, rezar y presentar las ofrendas principales y dirigir la actividad de la totalidad de los hombres presentes en la fiesta. No es aquí fugar para discutir sobre la naturaleza de su cargo. Baste con decir que no sacrificaré a la moda que quiere que los especialistas de la religión tradicional reciban automáticamente el nombre de " chamanes » y prefiero guardar el término local. Ayuda a los « abuelitos del pueblo » un cuerpo de responsables nombrados cada año al mismo tiempo que las otras 
autoridades, cuerpo que comprende cuatro mayo (un primero ayudado por otros tres) y una decena de jóvenes, el término mayo proviene del español mayor. Corresponde al primer mayo ayudar a los « abuelitos del pueblo », mandar a que los jóvenes vayan a cortar las hojas y las flores y supervisar la confección de las ofrendas. Los mayo representan, pues, una clase de cuerpo religioso tradicional rotativo que ayuda a los " abuelitos del pueblo », quienes ocupan su cargo de manera casi permanente.

La ofrenda que vamos a presentar en este artículo forma parte de los rituales de cambio de autoridades municipales y es dirigida al Fuego Nuevo.

\section{EL FUEGO NUEVO}

En un momento de la semana ritual de enero, los « abuelitos del pueblo » y las autoridades realizan una ofrenda al Fuego, mbatso en tlapaneco, traducido en español como « Señor Lumbre ». Al contrario de las otras ofrendas que se depositan en la periferia del territorio comunal, ésta se hace en el centro del pueblo, en uno de sus locales públicos.

Todas las localidades de los municipios de Zapotitlán Tablas y Acatepec tienen una « casa de topiles » en la que arde una gran lumbre alimentada perpetuamente por tres troncos de árboles. Es la «lumbre del pueblo »; además, tiene la ventaja de calentar a los responsables civiles, quienes, en esa región de hábitat disperso, se hospedan en la « casa de topiles » cuando su cargo requiere su presencia en el lugar. Esta lumbre es la que se apaga durante la semana ritual, y se vuelve a encender después de presentar la ofrenda. En la noche que sigue esta ceremonia, los vecinos del pueblo apagan las lumbres de sus casas y vienen a tomar un poco de la nueva para sus propios hogares.

Los lectores especialistas de Mesoamérica seguramente reconocieron en esa descripción ciertas características bien conocidas del dios mexica del Fuego : Xiuhtecuhtli-Huehueteotl. Esta divinidad estaba claramente relacionada con el centro (de la casa, del templo o del universo) como la representa el Códice Fejérváry-Mayer (lam. 1). Además, Xiuhtecuhtli era el Señor del Año o del Tiempo, asociado con el registro de los periodos anuales, cuadrienales, octoenales y seculares. Las más conocidas eran las fiestas celebradas en cada « atadura » del siglo mexica, es decir, cada 52 años, cuando el pueblo entero apagaba sus lumbres mientras una nueva era encendida haciendo girar un palo sobre un agujero practicado en una tabla encima del pecho de un cautivo sacrificado en la cima del monte del Huizache. Luego se quemaba completamente el cuerpo del sacrificado y unos indios corrían para llevar la nueva lumbre en unas «teas de pino » a cada uno de los pueblos de los alrededores de Tenochtitlán 9 .

La ofrenda al Fuego Nuevo que vamos a presentar tiene claramente la finalidad de iniciar un periodo de tiempo, durante el cual mandarán las autoridades municipales anuales. En Apetzuca, la ceremonia se realiza una vez al año, en enero ; pero en Tres Cruces, se celebra dos veces, la primera en enero, y la segunda en junio. En esa comunidad, pues, el periodo que cubre la nueva lumbre se extiende más o menos entre el solsticio de invierno (fines de diciembre) y el solsticio de verano (junio); se vuelve a encender una nueva lumbre en la primera semana de junio para el periodo que se extiende entre el solsticio de verano y el de invierno ${ }^{10}$. En ambos casos, el fuego nuevo 
abre un periodo que corresponde a un «sol»: en Apetzuca, el sol que rige entre los solsticios de invierno; en Tres Cruces, el que rige de un solsticio al otro. Esa idea corresponde a la costumbre local de dar el nombre de «luz » a la vez al sol y a la lumbre ${ }^{11}$. Así coinciden el ciclo solar con el periodo político simbolizado por el fuego.

\section{LA ORRENDA AL FUEGO NUEVO : BL MODELO}

De las observaciones realizadas en los dos pueblos mencionados, se desprende un modelo de ofrenda al Fuego. Cabe hacer notar que solamente la comparación entre las ofrendas efectivamente realizadas en cada uno de estos pueblos me ha permitido extraer una matriz común que voy a exponer. Por el momento, no mencionaré en detalle los números de los objetos contados y me concentraré en la estructura misma de la ofrenda.

\section{La construcción del cuadrado de leña}

Una primera etapa consiste en construir el nuevo Señor Lumbre con unos leños de ocote colocados en cuadrado unos sobre otros, para elaborar una clase de caja : se deposita, al este, un leño en el suelo y, a un metro de distancia y paralelamente, un leño al oeste ; perpendicularmente y apoyándose sobre estos, un leño al norte, y uno al sur. Sobre el cuadrado así formado, se siguen acumulando los leños (Figuras 1 y 2). El número total de leños es propio del Fuego. De esta manera, se elabora una representación efectiva de la deidad obtenida por medio de dos de sus características : su número (escogido de manera arbitraria por cada pueblo) y el cuadrado. Como para los antiguos mexicas, el Fuego se encuentra en medio de los cuatro rumbos del universo. Cada lado de la caja de lumbre corresponde a un punto cardinal, lo que significa que sus ángulos señalan direcciones a medio camino de cada uno de los puntos cardinales, a semejanza de la Lámina 1 del Códice Fejérváry-Mayer. Pero el cuadrado de Fuego tiene otro simbolismo asociado : « es como un corral, dentro tiene su pueblo, no va a pasar otra gente que hace mal, no puede pasar porque es un corral ». En otros términos, el cuadrado aparece también como una representación del pueblo en medio de (y protegido por) los cuatro rumbos. Es como una imagen miniaturizada del centro de la localidad rodeada por los puntos sagrados de la periferia de su territorio, donde se depositan las ofrendas de manera simultánea en la noche de viernes, ritual que tiene por objeto alcanzar la protección simbólica de la comunidad, como dentro de una caja ${ }^{12}$.

Hay que señalar que el Códice Vindobonensis, uno de los códices «mixtecos» de contenido religioso y genealógico, representa en varias ocasiones el dibujo de un cuadrado, en el que reconocemos la construcción del cuadrado de leña tal como lo realizan todavía los tlapanecos (Figura 4).

\section{La ofrenda vegetal}

La ofrenda vegetal se dispone en medio del cuadrado de leña, en Apetzuca, y a su lado, en Tres Cruces. En el primer caso, la ofrenda se quema al encender el fuego en el cuadrado, y en el segundo lugar, se prende fuego primero al cuadrado y se tira después 


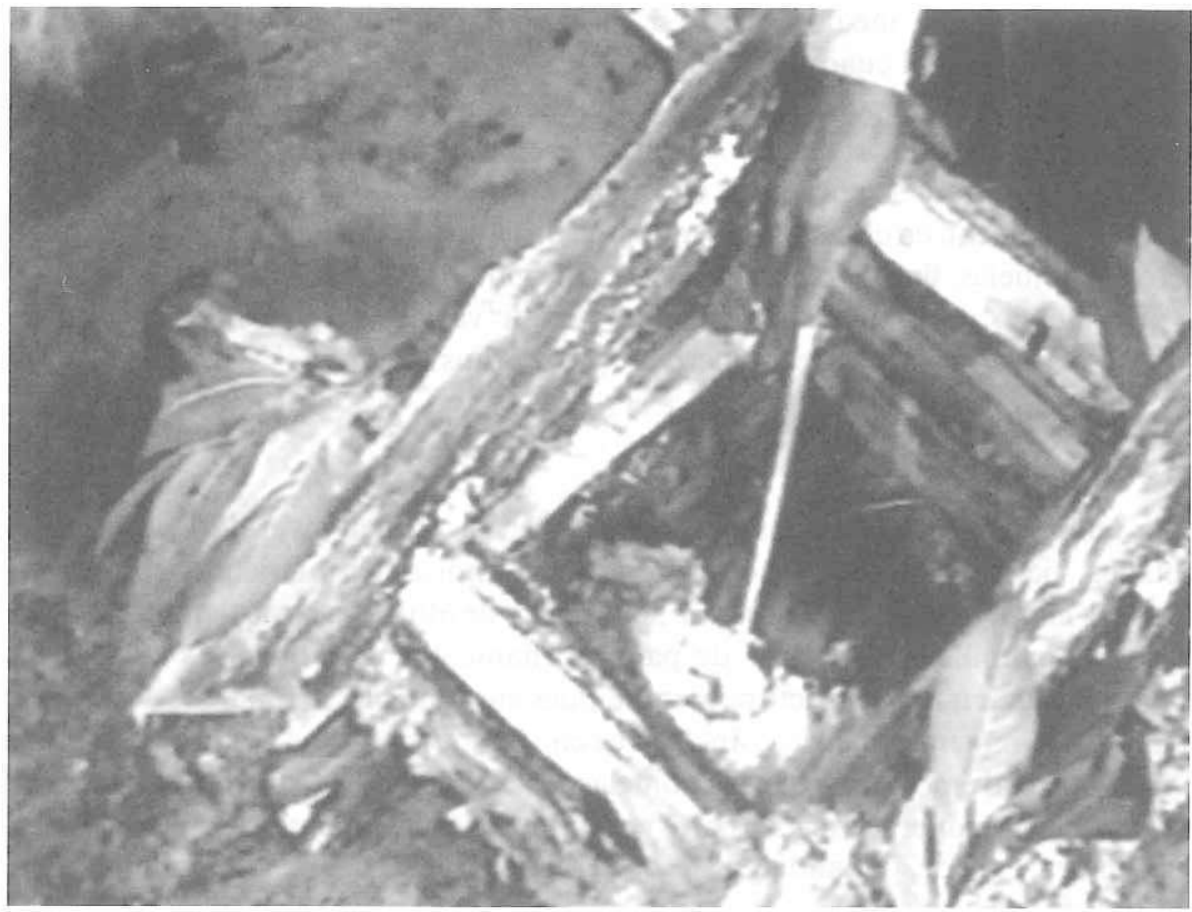

FIG. 1. - El cuadrado de leña representando el Señor Lumbre en Apetzuca

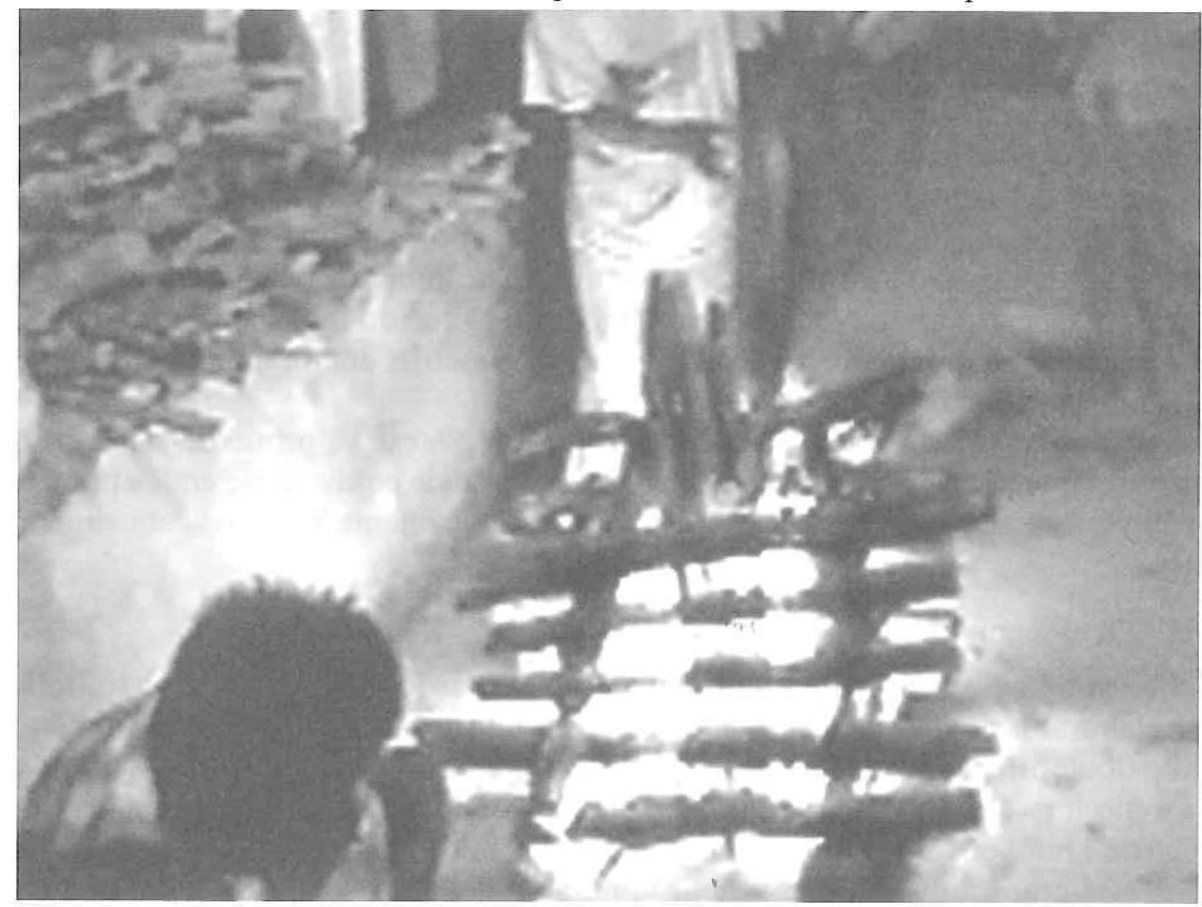

FIG. 2. - El cuadrado de leña representando el Señor Lumbre en Tres Cruces 
la ofrenda vegetal en medio de él. Así, al final, la ofrenda vegetal está destinada a quemarse junto con el cuadrado de leña.

Esta ofrenda se deposita de manera estrictamente orientada en el espacio. El « abuelito » se acuclilla a un lado del cuadrado de leña, mirando hacia el oriente, de modo que la lumbre se encuentre entre él y el oriente. Los objetos elaborados con vegetales se colocan en el suelo siguiendo una orientación espacial rigurosa : la base de las hojas, hojuelas, flores y velas debe estar dirigida hacia el oriente.

El principio de la ofrenda vegetal es repetir varias veces, con varios vegetales dispuestos de varias formas, el número propio del dios Fuego. Así se pueden distinguir varios niveles :

\section{A. La base o cama}

Se realiza con los vegetales que constituyen el primer nivel de la ofrenda. En Apetzuca, tierra fría a 2000 metros de altura al norte del municipio, son hojas de helechos (nikto') y en Tres Cruces, a 1500 metros de altura en la vertiente del Pacífico, hojas de "palmilla ", una clase de palma ornamental. Las hojas de helecho y de palmilla presentan una estructura común, pues sus hojuelas se reparten de cada lado del tallo de manera simétrica. Inclusive, en Tres Cruces, los hombres toman un cuidado especial en verificar que las hojuelas se desprendan del tallo exactamente en el mismo lugar de manera a formar pares equilibrados. Obviamente el principio que rige la estructura, es el de « dualidad " y esos vegetales son escogidos por la implantación simétrica de sus hojuelas.

Varias hojas de helechos o palmilla, en números contados, se depositan en el suelo para formar la base de los niveles superiores.

\section{B. En el primer nivel : los manojos de hojuelas}

El primer nivel de la ofrenda se realiza con los helechos o palmillas. Sus hojuelas se desprenden del tallo, se cuentan y se juntan de manera a formar unos manojos. Se repiten el número de hojuelas y el número de manojos, como, por ejemplo, para formar 24 manojos de 24 hojuelas cada uno. Este número puede variar según el pueblo, pero, en todo caso, se utiliza el número reconocido localmente como propio del Fuego. Como lo veremos, es posible, pero no necesario, añadir manojos atribuyéndoles números con otros significados.

Este nivel es el más potente (" tiene más fuerza, por eso va primero ») y, al mismo tiempo, el que puede atraer mayores peligros en caso de equivocarse en los números, por cuyas razones los manojos son elaborados únicamente por los « abuelitos del pueblo ».

\section{En el segundo nivel : las mechas}

El segundo nivel de la ofrenda se realiza con base en los hilos de algodón utilizados para elaborar las velas que se presentan en un carrete de hilos dobles. El abuelito dobla el hilo doble alrededor de su mano el número de veces deseado y lo corta. Obtiene así una " mecha » (guma notrigo, « mecha contada ») del tamaño de una palma de mano, hecha de 4 hilos en caso de doblar una vez el doble hilo, 8 hilos en caso de doblarlo dos veces, etcétera. La finalidad es repetir el número del dios del Fuego con este nuevo material, por ejemplo obteniendo 24 mechas de 4 hilos cada una. El paquete de 
mechas se baña luego en cebo, de manera que cada mecha se parezca a una vela en miniatura. Pero la mecha no se enciende, sino que se coloca encima de los manojos. Se dice que « también es potente la mecha ».

Se reconocen en estas mechas los hilos torcidos de algodón que el cura Hernando Ruiz de Alarcón aseguraba, en 1629, haber visto en la región nahua de Guerrero :

"Con esto salía (el penitente) a su viaje, llevando para su primera ofrenda, copal que es incienso desta tierra, y unas madejas de hilo grueso de algodón mal hilado, al modo del que se hace el pabillo, o algún pañuelo tejido de aquel genero de hilo, que por esto llaman Poton ${ }^{13}$ : quiere decir poco torcido que a trechos descubre el algodón, $\mathrm{y}$ así lo he hallado yo en las ofrendas de los montones de piedra [...] » (Hernando Ruiz de Alarcón, Tratado, cap. IV, « De la adoración y sacrificio que hasian en los cerros a los idolos, y montones de piedras por los caminos que estan señalados hasta hoy ", p. 140).

"He hallado en los cerros muchas ofrendas de copal, que es incienso desta tierra, y madejas de hilo y pañitos de lo que llaman Poton, mal hilado, y candelas y ramilletes, unas muy antiguas y otras frescas » (Ibid., cap. II, p. 134).

\section{En el tercer nivel : las cadenas de hojas y flores}

El tercer nivel está compuesto de cadenas o « rosarios » de flores y hojas. Con un lazo de majahua o un hilo de plástico o algodón, según el caso, se trata de realizar cadenas de flores o de hojas enrolladas como cigarros, que forman una rueda. Este nivel es menos « potente » que los que preceden, pero es grande el número de cadenas requerido e importante el trabajo necesario. Por esa razón, todos los hombres disponibles participan en su confección, según el lugar, las autoridades civiles, los abuelitos y los jóvenes ayudantes del mayo.

Como mínimo, hay que repetir el número del Fuego ya mencionado en los niveles anteriores. Así, para imitar las 24 mechas de 4 hilos, se elaboran 24 cadenas de 4 flores u hojas. Pero este nivel, menos peligroso y estructurado que los demás, es el lugar de una gran variedad de formas y vegetales.

Las flores son muy preciadas pero no se dan en cada época y, además, puede ocurrir que no se encuentren en número suficiente. En este caso, en lugar de flores, se utilizan las hojas.

Las flores fueron utilizadas en Tres Cruces únicamente en el mes de junio : fueron flores de Plumeria rubra (en tlapaneco, ri’so, traducido en español como « flor de juberito »). Las flores cortadas en Apetzuca en enero fueron Tagetes erecta (la clásica « flor de muerto » o sempoalsochil), la más preciada, y las brácteas rojas de la Flor de Noche Buena.

Se utilizaron hojas de laurel (ina rahto ; Litsea glancescens, Litsea neesiana ${ }^{14}$ ) en Tres Cruces y de una clase de Salvia (ina skemba) en Apetzuca, todas presentan la característica de tener un olor fuerte. Ambos pueblos utilizan además una hoja trilobulada (ina ri'xua).

Las formas de las cadenas son diversas. En Apetzuca, se elabora una cadena grande de Tagetes erecta o de brácteas de Flor de Noche Buena, la que se corta luego en trozos de cuatro flores o brácteas cada uno. Todas las otras cadenas forman una rueda de flores o de hojas cuyo número rebasa ocho. 


\section{E. La cadena-collar}

Una cadena especial termina esta parte de la ofrenda. Se puede decir que es un « collar » destinado a concluir la representación del Fuego realizada en el cuadrado de leña y la ofrenda vegetal. El collar de flores es un símbolo honorífico destinado a honrar una «persona » ( $x a b u$, en tlapaneco) como, por ejemplo, los responsables civiles en cierto momento del ritual. «El señor Lumbre es una persona como nosotros », y, por lo tanto se termina la confección de su imagen con esta muestra de veneración.

\section{F. La separación : el algodón}

Una vez concluida la representación de la deidad en la ofrenda vegetal, se coloca encima un pequeño pedazo de algodón en greña. Me parece que su función principal es la de separar la primera etapa ya concluida de la ofrenda, antes de volver a encimar unos objetos con otro significado.

Las explicaciones recogidas fueron diversas : " es como una chamarra que se ofrece ». « Es ropa para Lumbre ». « El significado es diferente según la ofrenda ; en una ofrenda a Lumbre o a la Tierra, es un vestido. En una ofrenda a San Marcos (el cerro), representa una nube ». «La hoja es como una mesa, el algodón como un mantel » sobre el que van a presentar la comida a la deidad.

Estas frases recuerdan las que recogió Hernando Ruiz de Alarcón en la región nahua de Guerrero y continúan la cita sobre los hilos gruesos de algodón (ver supra) :

« acompañaban la ofrenda con el que llama quauhamatl, que es una manera de papel blanco como lienzo que se hace en Tepoztlan de una corteza de árbol blanda ; en este papel iba envuelta la ofrenda y servía con el algodón como para que se vistiese el dios o ídolo a quien se ofrecía, y así responden hoy los que ofrecen, que es para que se vistan los Angeles que andan en las nubes, o portillos y encrucijadas de los caminos " (Ruiz de Alarcón, Tratado I, cap. Iv, subrayado por nosotros).

Según este texto, el pabillo de algodón grueso (las « mechas » de nuestra ofrenda tlapaneca referidas supra) tenían el mismo objeto que el lienzo de papel (el algodón en greño de nuestra ofrenda tlapaneca) : vestir al « dios o ídolo». Como en el caso que estudiamos, el pabillo iba primero y el papel, al final, cubría la totalidad de la ofrenda. En la actualidad, aparte de las « mechas » y del algodón, la ofrenda va envuelta en una gran hoja en Tres Cruces, y en una bolsa de plástico en Apetzuca. Finalmente las ofrendas envueltas de este modo en estos pueblos llegan a parecerse a la ofrenda envuelta en una clase de « lienzo » que aparece al lado del cuadrado de leña en el Códice Vindobonensis (Figuras 3 y 4 ).

\section{Los regalos}

Terminada esta primera etapa de la ofrenda, los objetos depositados a continuación pertenecen a una nueva categoría : los dones al Fuego, que reciben el nombre español de « recompensa ». «Es como hacer mole para una persona y regalarle su refresco $»$. 


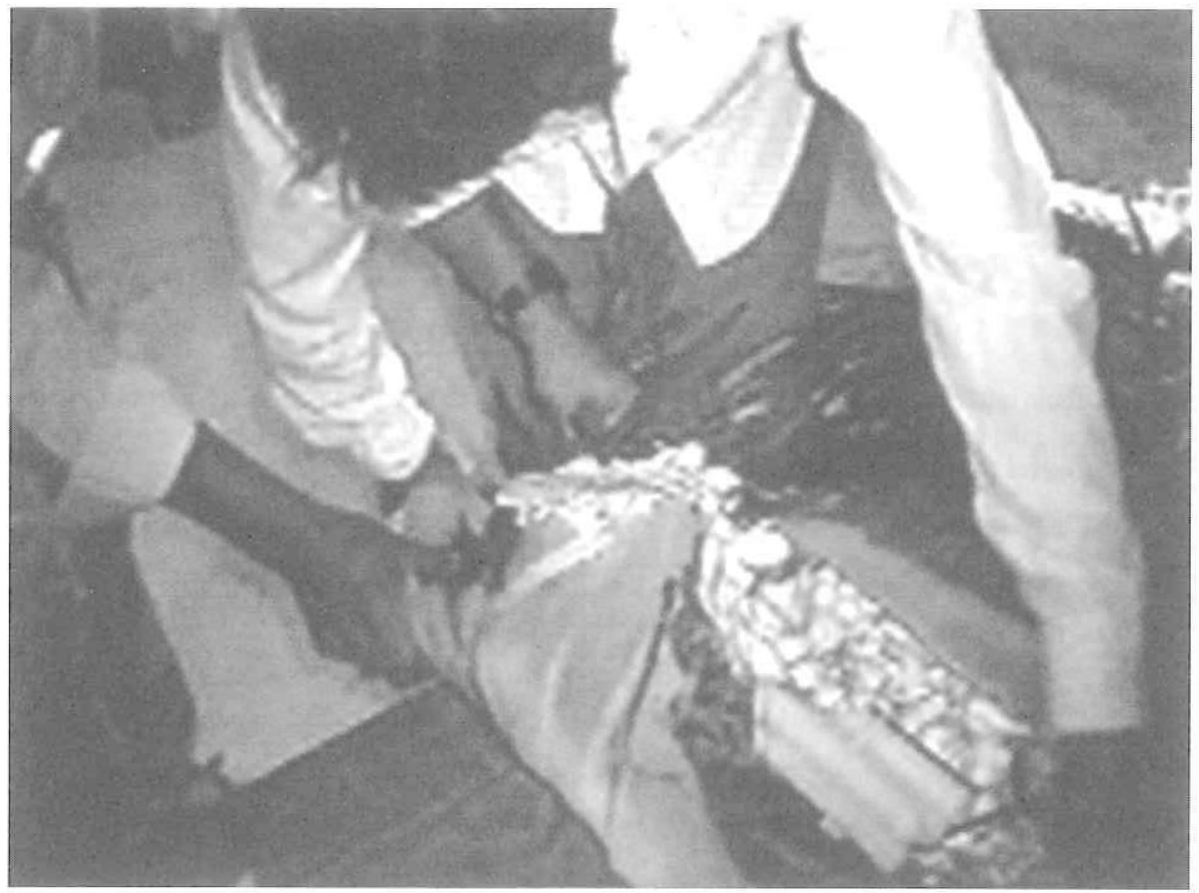

FIG. 3. - La ofrenda vegetal amarrada destinada al Fuego en Tres Cruces

\section{A. La comida}

En Apetzuca, se ofreció un huevo, y en Tres Cruces, un pollo degollado ; su sangre fue salpicada encima de la lumbre ardiente en el cuadrado de leña.

\section{B. La bebida}

Fue ofrecida solamente en Tres Cruces, donde se llenaron de « chilote » cuatro trozos de bambúes.

C. El tributo en metálico

En Tres Cruces, una vez la ofrenda vegetal y la « recompensa » de pollo y chilote puestas en el cuadrado ardiente de lumbre, el abuelito salpicó la lumbre con un polvo metálico que llamó « oro ». A mi pregunta, contestó que este polvo se compraba en el mercado de Ayutla en los puestos que venden también el copal. En Apetzuca, antes de encender el fuego, el abuelito colocó encima de la ofrenda un pedazo de mineral proveniente de una veta local ${ }^{15}$.

El simbolismo del metal (llamado en Apetzuca : «platinas millonarios ») es el mismo en ambos pueblos : se trata de un tributo en metálico pagado a cambio de la vida del pueblo y del uso de la tierra : « Este pueblo está comprado a la Tierra ». «El metal significa compra de la vida, es como la moneda ». " Es la compra de la vida de los hombres, mujeres, niños del pueblo para el año ». El significado asociado es : 


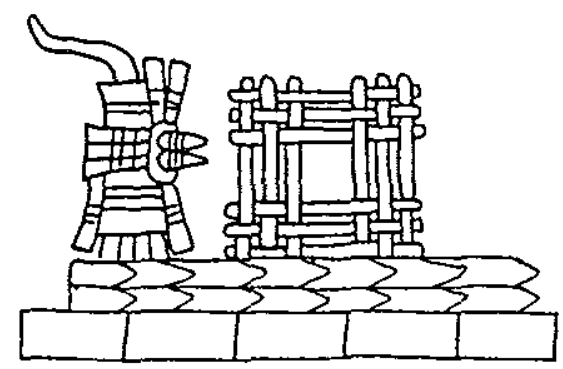

Fig. 4. - Dibujo interpretado en este artículo como un cuadrado de leña y una ofrenda amarrada, sacado de la Lámina 17 del Códice Vindobonensis (en F. Anders, M. Jansen \& L. Reyes García : Origen e Historia de los Reyes mixtecos. Libro explicativo del llamado Códice Vindobonensis, 1992)

« para tener dinero », se supone que el don de dinero debe atraer la riqueza en dinero al pueblo, del mismo modo que el sacrificio de un pollo tiene por consecuencia la multiplicación de los pollos caseros. Este tributo en metálico tiene, pues, el doble significado de pago (un tributo o una renta) y de reciprocidad (se ofrece algo para recibirlo de vuelta).

\section{Los intermediarios}

Por fin, ciertos actos y objetos son necesarios para hacer llegar la ofrenda a su destino. En primer lugar, las autoridades civiles tienen que soplar sobre la ofrenda vegetal para indicar quiénes son los beneficiados del ritual. Soplan en nombre de todos los habitantes de su pueblo que no necesitan participar en persona para « recibir su año ", es decir, el derecho de vivir un poco más en ese mundo.

Las velas son los vehículos de mayor importancia, porque « Lumbre está sentado en ellas », y lleva los mensajes a donde deben llegar. Cabe hacer notar que los hilos de las velas también son contados, y para el Fuego, son cuatro (es decir, dos hilos dobles) como las velas mismas. El abuelito reza la parte más importante de su plegaria con las cuatro velas prendidas en las manos y, después, las coloca en el suelo, en fila delante del Fuego, en Tres Cruces, y a los lados del cuadrado de leña, en Apetzuca, donde las deja hasta que se acaben. Las velas más gruesas, que se consumen lentamente, permiten alcanzar una vida más larga.

La resina del copal, echada en las brasas de la lumbre, tiene una función semejante. La ofrenda se sahuma cuatro veces, antes de la ceremonia del soplo y el humo del copal acompaña todas las plegarias y la quema del cuadrado de lumbre y de las velas.

El modelo de ofrenda que terminamos de presentar proporciona el marco que permite describir las costumbres propias a los dos pueblos considerados, e introducir el problema del uso de los números.

\section{EL FUEGO NUEVO EN APETZUCA}

La ofrenda realizada en Apetzuca comprende la repetición sencilla del número del Fuego : 24 (Figura 5). 
Regalos

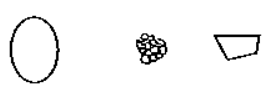

Tercer nivel

Segundo nivel

Primer nivel

Cama polvo metálico

un huevo

un pedazo de copal

un pedazo de mineral

pedazo de algodón

1 cadena de 100 flores

24 trozos de 4 flores

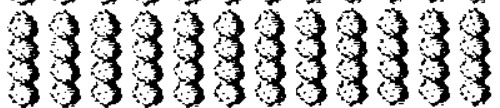

88888888888

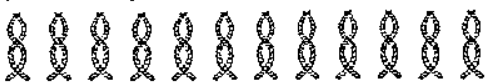

24 mechas de 4 hilos

24 manojos de 24 hojuelas
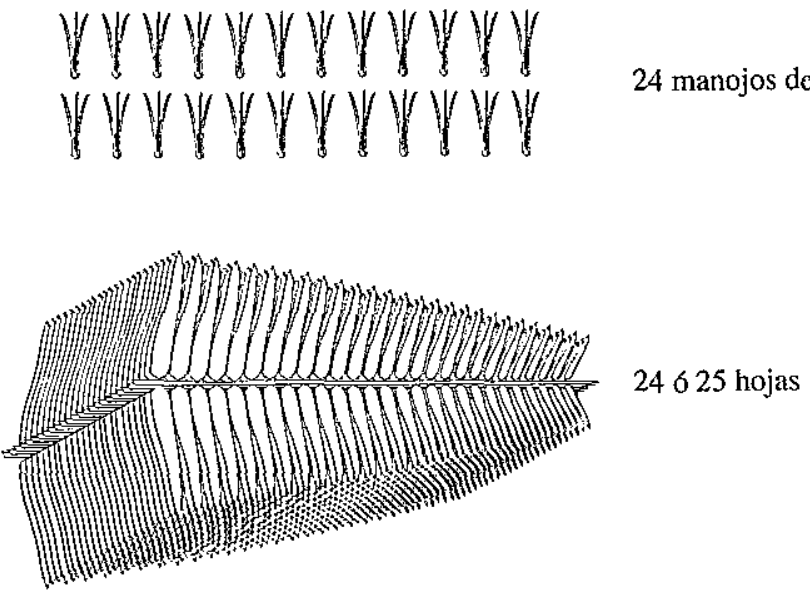

FIG. 5. - La ofrenda vegetal al Fuego en Apetzuca 


\section{La construcción del cuadrado de leña}

El cuadrado está construido con 24 leños puestos en cuadrado.

\section{La ofrenda vegetal}

A. La base o cama : 24 ó 25 hojas de helechos.

B. En el primer nivel : 24 manojos de 24 hojuelas de helechos.

C. En el segundo nivel : 24 mechas de 4 hilos cada una.

D. En el tercer nivel : 24 trozos de cadena de 4 flores de Tagetes erecta.

E. El collar : está formado de una cadena de 100 flores de Tagetes erecta puesta encima del cuadrado de leña, dentro del cual se encuentra la ofrenda vegetal. Es posible que las 100 flores signifiquen el tiempo, el periodo que abre el Señor Lumbre y para el cual el pueblo pide su vida.

Las otras etapas de la ofrenda son comunes con el otro pueblo y no las vuelvo a describir.

\section{El fUeGo NUEvo en TRES CRUCES}

La ofrenda realizada en Tres Cruces es más compleja (Figura 6).

\section{La construcción del cuadrado de leña ${ }^{16}$}

El cuadrado está construido con 39 leños en total. Una parte de ellos sirve para formar el cuadrado y los demás se ponen verticalmente adentro del cuadrado. El 39 es el número de la Lumbre por la razón siguiente : Lumbre está constituida de 4 hombres que corresponden a las 4 direcciones. Como 8 es el número del hombre, 4 hombres son $4 \times 8=32$. Pero « detrás de cada hombre, hay una mujer », y Lumbre también tiene su esposa. Como el número de la mujer es 7, la Lumbre entera está formada de 4 hombres más una mujer, es decir, $4 \times 8+7=39$.

\section{La ofrenda vegetal}

A. La base o cama : 8 hojas grandes de palma ornamental.

B. En el primer nivel (Figura 7) :

a) Un manojo de 100 hojuelas de palma y un manojo de 50 hojuelas de palma. Representan « el empiezo del año », lo que significa el periodo de tiempo de vida que piden los vecinos del pueblo.

b) 34 manojos de 34 hojuelas de palma. Representan el Fuego, dado que 34 es su número.

c) 8 manojos de 8 hojuelas de palma y 7 manojos de 7 hojuelas de palma. El significado se desprende del simbolismo del 8 (hombre) y 7 (mujer). Expresado en hojuelas de palma y en este nivel de la ofrenda, significan el maíz (8, masculino) y el frijol (7, feminino). Juntos representan la cosecha o productos de la tierra que son pedidos en la ofrenda. 

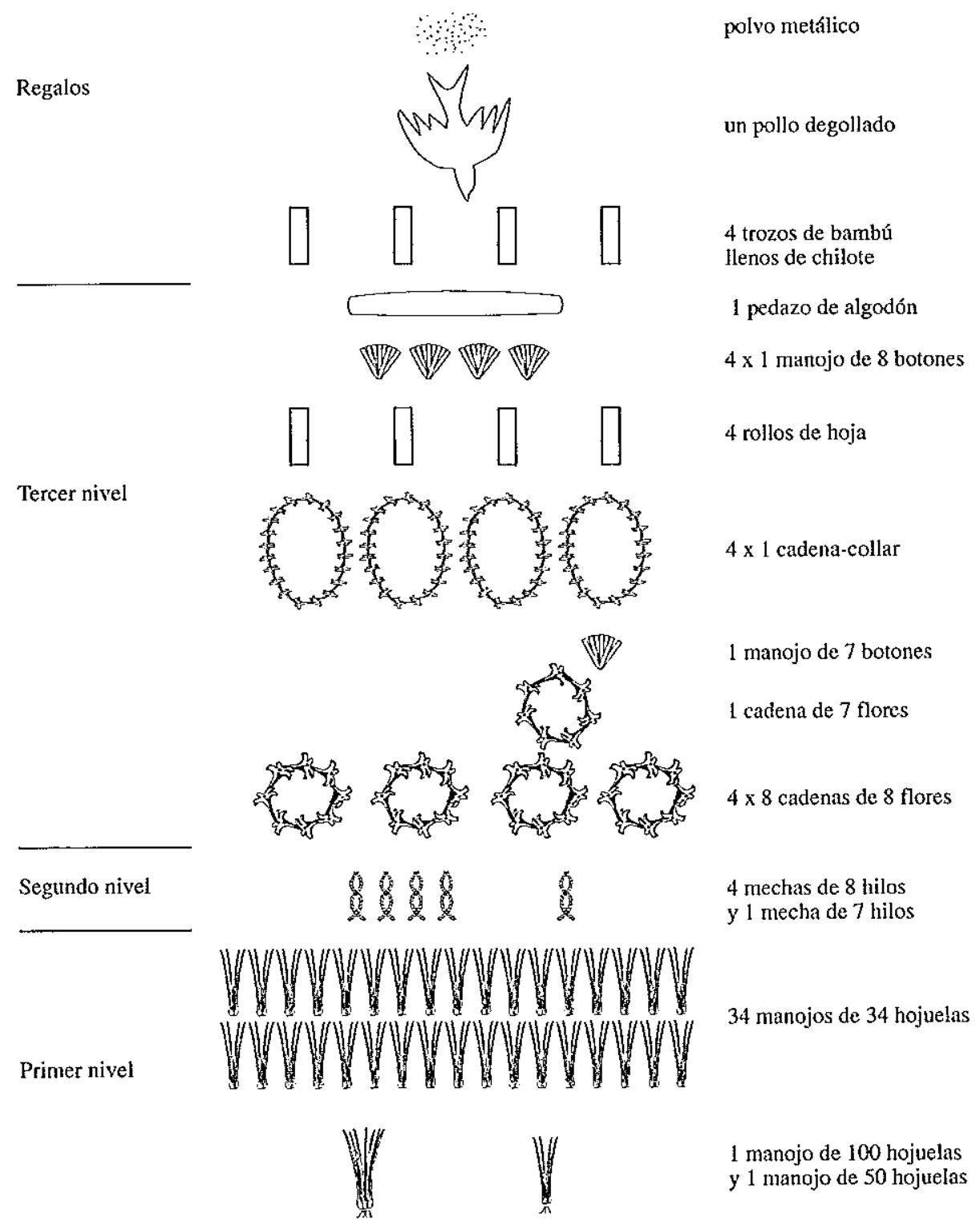

1 manojo de 100 hojuelas y 1 manojo de 50 hojuelas

Cama

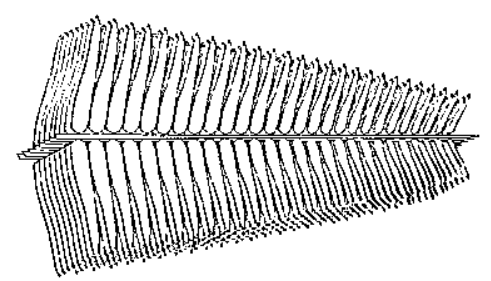

8 hojas

Fig. 6. - La ofrenda vegetal al Fuego en Tres Cruces 
C. En el segundo nivel : 4 mechas de 8 hilos cada una y una mecha de 7 hilos. El significado de 8 y 7 es de nuevo el de hombre y mujer, pero aquí sirve para designar el Fuego. Las 4 mechas de 8 hilos significan los 4 hombres-Fuego que corresponden a las 4 direcciones (este, oeste, norte y sur). La mecha de 7 hilos es la mujer del Fuego.

D. En el tercer nivel (Figura 8) : El Fuego está representado bajo la apariencia de los 4 hombres que lo componen. Es decir que se repite 4 veces la representación de uno de estos personajes, realizada en hojas de encino (en enero) y flores de Plumeria rubra (en junio).

a) 4 veces 8 cadenas de 8 flores. Basadas en el simbolismo masculino del 8 , las 8 cadenas de 8 flores representan un hombre-Fuego. Hay 4 montones de 8 cadenas de 8 flores para representar a los 4 hombres-Fuego.

b) 7 cadenas de 7 flores, una sola vez. Basadas en el simbolismo femenino del 7 , representan la mujer única de los 4 hombres-Fuego.

c) 4 collares de flores no contadas para honrar cada uno de los 4 hombres-Fuego representados en forma de las 8 cadenas ya mencionadas.

d) 4 rollos de hoja trilobulada que completan la representación de los 4 hombresFuego.

e) 4 manojos de 8 botones de flor; que representan la casa de cada uno de los 4 hombres-Fuego.

f) Un manojo de 7 botones de flor; que representa la casa de la mujer-Fuego. Este manojo se coloca junto a (b) las 7 cadenas de 7 flores.

\section{EL USO DE LOS NÚMARROS}

Las diferencias notadas entre las ofrendas de los dos pueblos nos permiten plantear la cuestión del uso de los números en ellas.

Antes de empezar el análisis, hay que mencionar el principio de dualidad, principio general que rige todo el pensamiento tlapaneco y ya ha sido el objeto de una abundante literatura por parte de los especialistas de Mesoamérica. En función de este principio, cualquier entidad se puede dividir en dos entidades portadoras de un principio masculino y femenino ${ }^{17}$. Enunciado en unas frases como « detrás de cada hombre hay una mujer » o " cualquiera tiene su compañero », este principio estructura el pensamiento tlapaneco sobre todas las cosas : el tiempo (el año se divide en dos por medio de los solsticios de verano e invierno), el cuerpo humano (dos manos y dos pies), la familia (dos padres y dos hijos), la cosecha (maíz y frijol), etcétera.

\section{El simbolismo numérico}

La elaboración de los objetos contados se hace con base en unos cuantos números simbólicos, que son, para los dos casos considerados : 4, 24, 34, 8, 7 y 100.

El 4 representa a la vez el carácter completo de una persona y sus elementos constitutivos. Así, me han dicho que una persona humana tiene cuatro miembros (dos manos, dos pies), una familia se puede simbolizar por cuatro personas (dos padres, dos hijos, es decir, una pareja masculina y femenina en la primera generación, y lo mismo en la segunda). En el caso del Fuego, la deidad se sienta en el centro del universo 


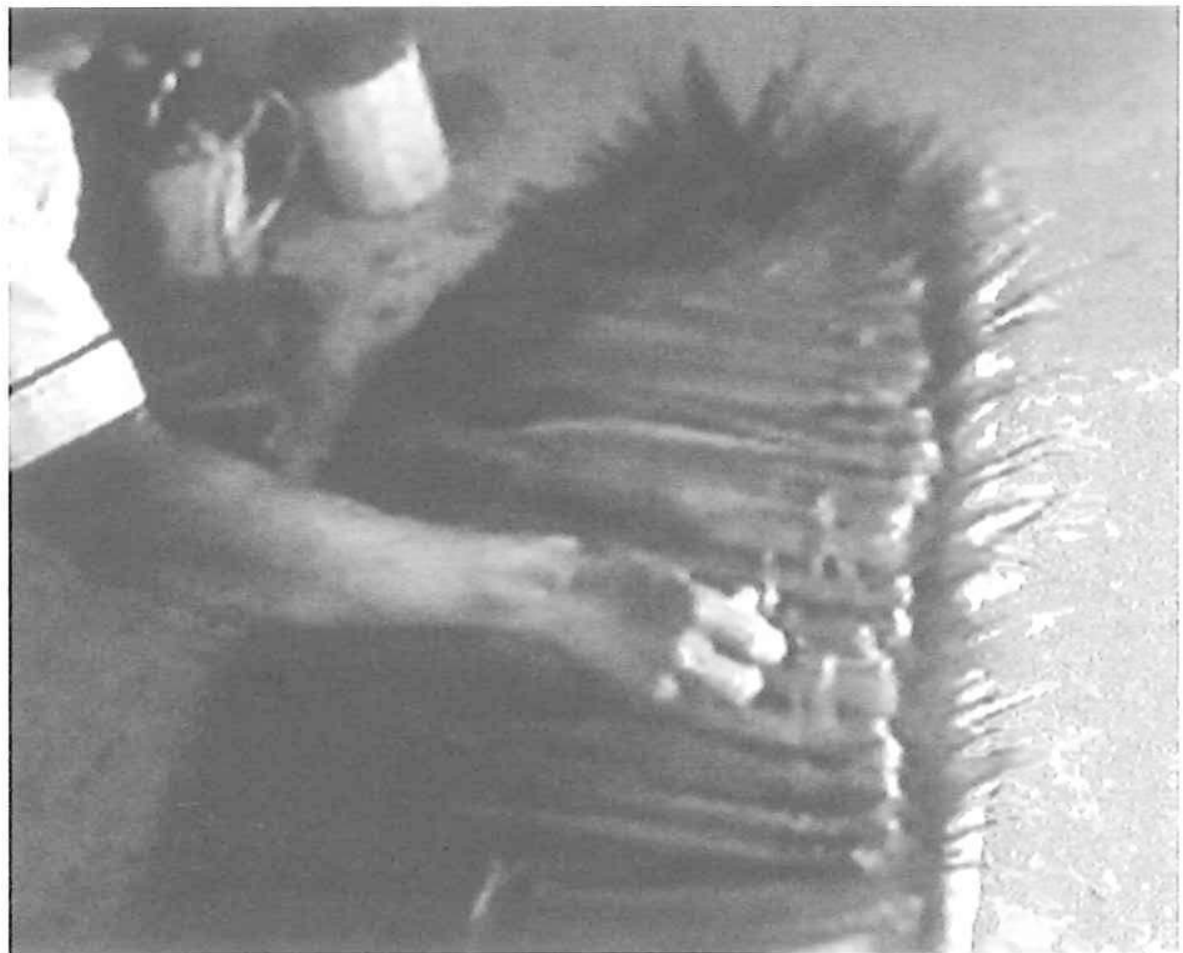

FIG. 7. - Primer nivel de la ofrenda al Fuego en Tres Cruces : los manojos de hojuelas

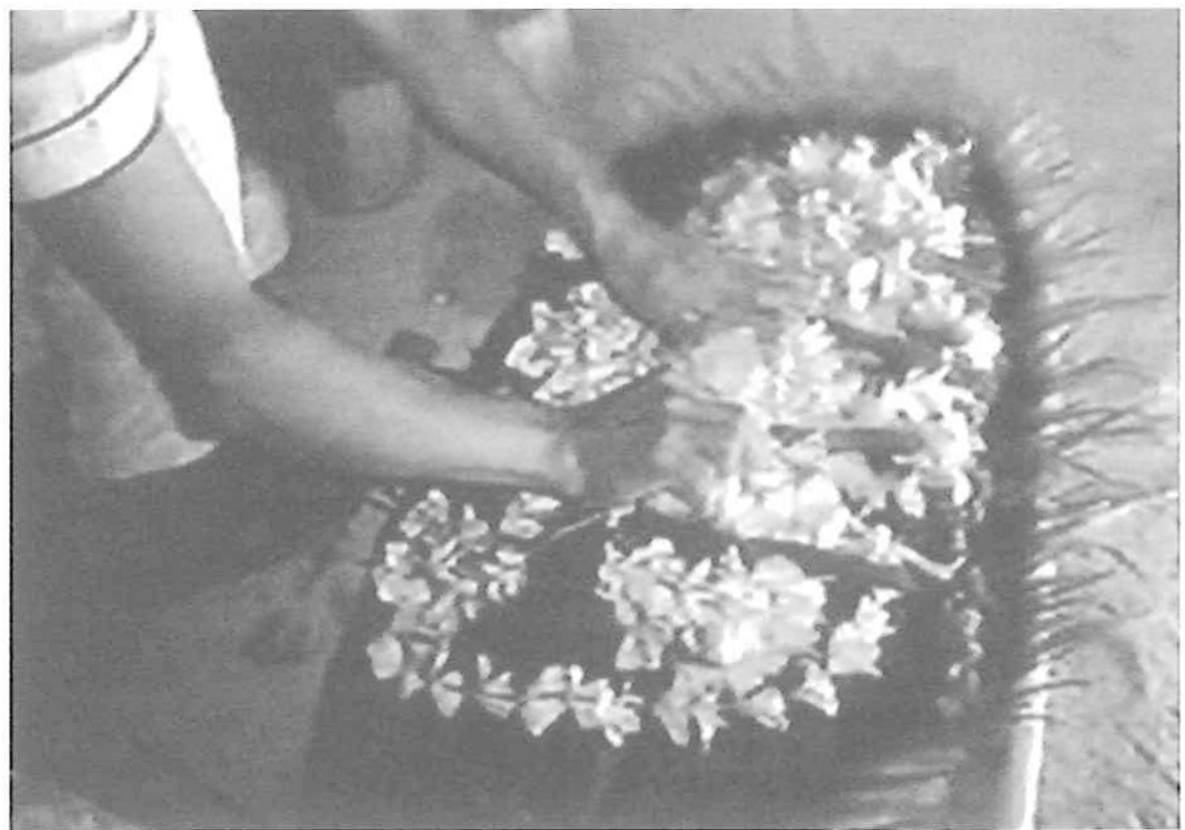

FIG. 8. - Último nivel de la ofrenda al Fuego en Tres Cruces : las cadenas de flores y el algodón 
constituido por cuatro direcciones. Esto está en conformidad con la creencia de los antiguos nahuas quienes llamaban al Fuego Nauhyotecuhtli (Señor del conjunto de Cuatro o, más bien dicho, Señor de la « Cuadruplidad»).

El 24, número del Fuego en Apetzuca, aparece por varias razones como el número perfecto de Lumbre ${ }^{18}$. Termina por el $4(20+4)$ y es divisible por $4(6 \times 4)$. Pero, además, y del mismo modo que los cuatro miembros se dividen en dos manos y dos pies, y que la familia se divide en dos personas padres y dos personas hijas, el 24 de Lumbre es divisible por $2(12 \times 2)$, y el 12 aparece como un número cargado de simbolismo. Al dividirse 24, me dicen que « deja 12 al este, y 12 al oeste ; y hay 12 meses en el año ». Quizá 12 evoca el año, es decir, el tiempo, y sabemos que el Fuego era el Señor del Tiempo entre los mexicas y lo sigue siendo entre los tlapanecos.

El número de base del Fuego en Tres Cruces es 34. Pienso que se trata de una evolución a partir del 24. En efecto, 34 termina por 4, cifra de los cuatro rumbos del universo y por consiguiente del Fuego, pero 24 tiene un valor numeral inferior $(20+4)$, mientras 34 se compone de $30+4$. Como lo demostraré más adelante, un número mayor tiene una eficacia mágica y religiosa mayor. Esto estaría en acuerdo con la preocupación manifestada en Tres Cruces de variar los números del Fuego, y preferir los que son altos. En efecto, el segundo número del Fuego en este pueblo es 39. Se obtiene por medio de una operación aritmética realizada con base en el número 4 (simbólico del Fuego), 8 (simbólico del elemento masculino) y 7 (femenino) :

4 (el Fuego $) \times 8$ (el hombre $)=32(\operatorname{los} 4$ hombres-Fuego $)+7($ su mujer $)=39$.

En Tres Cruces, el estrato de las cadenas de flores y hojas consiste en la representación individual de los cuatro hombres-Fuego (basado en los números 4 × 8) que nos recuerda con fuerza que el Códice Borgia (p. 46) ofrece una representación figurativa de los cuatro hombres-Fuego muy semejante a la representación abstracta proporcionada por los tlapanecos : un sacerdote taladra el Fuego en el corazón de una deidad, el humo sube y los dioses del Fuego se dispersan hacia las cuatro direcciones (Figura 9).

El 8 y el 7 representan en Tres Cruces el elemento masculino y el femenino. Según el estrato de la ofrenda, evocan al hombre-fuego y su mujer, o el maíz (masculino) y el frijol (femenino).

El 100 alude a un periodo de tiempo. Aparece en Apetzuca en la cadena-collar que adorna la representación completa de Lumbre (100 flores) y, en Tres Cruces, en el manojo de 100 hojuelas de palma, acompañado por « su compañero », el manojo de 50 hojuelas. Pienso que la existencia de estos dos últimos manojos se debe a la aplicación del mismo principio de dualidad, que quiere que cualquier entidad se pueda, y deba, dividir en dos.

\section{Atar para crear grupos}

Los números tienen un valor simbólico, el cual, al confeccionar la ofrenda, se encarna en un material vegetal. Para tal efecto, hay que agrupar flores y hojas : la atadura de los elementos vegetales sueltos permite la materialización del número. El medio es el hilo o lazo.

Así, cuando se confecciona un manojo de 24 hojuelas, una hojuela adicional sirve para atarlo. En un primer momento, se agrupan las hojuelas con la mano y la hojuela 


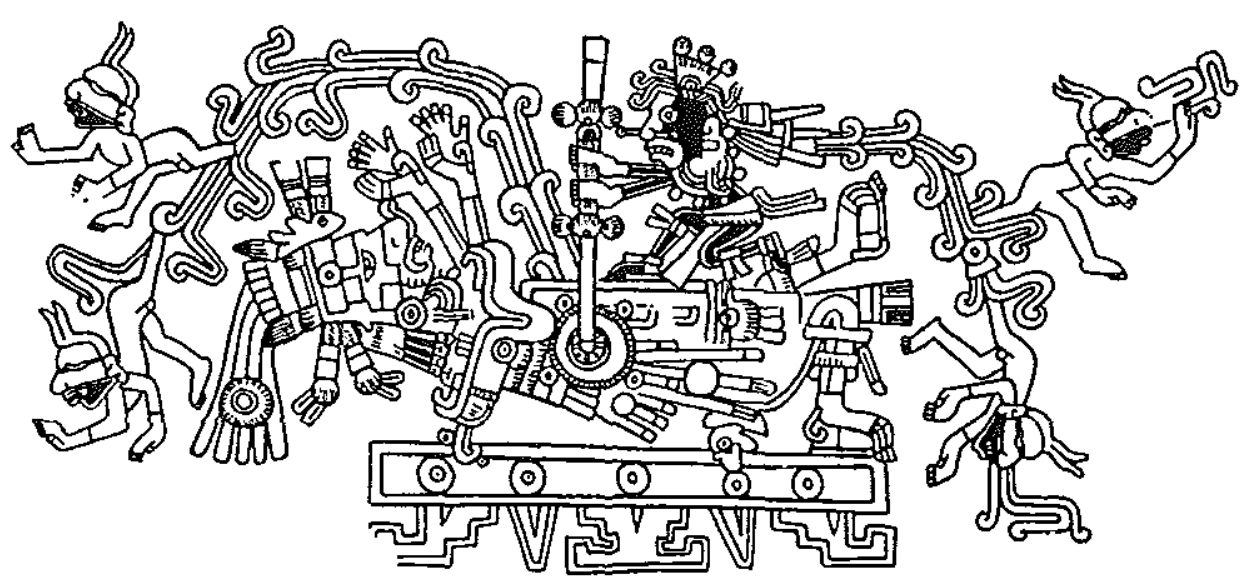

FiG. 9. - Los cuatro dioses del Fuego según el Códice Borgia, lámina 46

adicional enlaza su base para formar un bloque. Pero como, en función del principio de dualidad, cualquier entidad se compone de dos partes, la hojuela-lazo pasa verticalmente entre las hojuelas del manojo de manera a dividirlas en dos partes. $\mathrm{Al}$ mismo tiempo, la hojuela-lazo queda metida en medio del haz, formando una atadura sólida. De esta manera, el nudo queda integrado a la estructura misma del manojo.

Para confeccionar una cadena, existen dos métodos. Se atan cada hoja enrollada por medio de un nudo de modo que un mismo lazo las reúnan todas, o se ensartan las flores en un hilo por medio de una aguja. Luego un último nudo cierra la rueda.

« Es como si se amarra un animal, se amarra bien para que no se pierda, para que no se suelte »: la atadura simboliza la confección de un grupo que no se puede deshacer.

\section{Multiplicar para crear categorías semánticas}

La multiplicación permite poner los números en acción y crear categorías semánlicas, por eso se utiliza de manera sistemática. Se puede decir que ella es la que crea una entidad a partir de un número simbólico. Así, 4 simboliza el Fuego por sus cuatro rumbos, de ahí se forman 24 y 34 en los que descansa el mismo simbolismo. Pero construir el Fuego con vegetales requiere una multiplicación : 24 x 4, 24 x 24, 34 x 34, o 4 x 8 , rea lizada al formar 24 cadenas de 4 flores, 24 manojos de 24 hojuelas, etcétera. De la misma manera, 8 simboliza el principio masculino, pero construir la entidad hombre (sea hombre-fuego o hombre-maíz) quiere se multiplique 8 por 8 , de tal manera, por ejemplo, que el hombre-fuego se representa por 8 cadenas de 8 flores, y el hombre-maíz por 8 manojos de 8 hojuelas.

\section{La fuerza mágica de los números}

Los números no son únicamente un modo de crear categorías semánticas, es decir, no representan sólo un lenguaje. También están dotados de eficacia mágica. Los 
objetos contados con ciertos números no solamente « dicen » el nombre del Fuego, sino que, también, lo construyen y lo materializan. Por eso es que la ofrenda tiene realmente consecuencias benéficas para el pueblo, pero también requiere una preparación especial de los participantes (dieta y abstinencia sexual) y se puede volver sumamente peligrosa en caso de equivocarse de números o presentarlos en forma incompleta.

Los números altos están cargados de una fuerza y eficacia mayor. Esto no debe sorprendernos tratándose de una cultura en la que una larga vida (la posesión de muchos años) y una gran riqueza (la posesión de muchos pesos) otorgan la potencia. En consecuencia, no es una casualidad que el número de la mujer (7) se forme restando 1 al número del hombre (8), concebido como más fuerte.

Para otorgar a la ofrenda una eficacia mayor, un método consiste, pues, en aumentar los valores numéricos utilizados. Creo que este procedimiento es el que llevó los habitantes de Apetzuca a utilizar el 24 en lugar del 4, y los de Tres Cruces a utilizar el 34 en lugar del 24. Esa hipótesis tendrá que guiar mi futura investigación.

\section{RBFLEXIONES FINALES}

Las ofrendas observadas en los dos pueblos tlapanecos ostentan características comunes ; están constituidas de varios niveles con significados distintos.

En primer lugar, se representa o, más bien dicho, se construye el Fuego como un cuadrado de leños en el que descansa un simbolismo múltiple : el Tiempo (inicia un periodo de poder político, y un ciclo solar); el Espacio (está al centro de los cuatro rumbos); el Pueblo (como un centro protegido por los rumbos de su territorio)

Luego viene la ofrenda vegetal, que también es una representación de la deidad : se repite el número del Fuego en tres estratos sucesivos (manojos de hojuelas, mechas de algodón y cadenas de hojas y flores). Tengo la hipótesis que cada uno de estos estratos representa una parte distinta de la deidad ; los manojos serían su mero cuerpo, por eso tendrían la mayor eficacia, pero también atraerían mayores peligros en caso de equivocarse de números ; las mechas representarían sus vestidos, pues el algodón es originario de estas tierras tropicales y simboliza la indumentaria de los señores y dioses ; por fin, las cadenas y collares constituirían sus adornos ${ }^{19}$. Esta representación está dotada de eficacia, no sólo dice sino que hace, de ella depende el logro de los rezos.

El nivel superior es totalmente distinto, ya que consiste en dones de comida, bebida y metal.

Las cifras ofrecen el código que permite la representación de la deidad. El número, a partir de un simbolismo de base, se materializa en un objeto vegetal y adquiere así un valor semántico. Este uso de los números es muy alejado al que acostumbramos en nuestra sociedad. De manera espontánea, el antropólogo tiende a multiplicar y sumar las hojas y las flores para obtener un total. Yo lo hice, y la primera vez que vi 8 manojos de 8 hojuelas, enuncié : 64 ; para 34 manojos de 34 hojuelas : 1156. Encuentro reacciones de este tipo en otros libros de antropología, como el de Frank Lipp, quien describe varios rituales mixes de ofrendas contadas y efectúa sistemáticamente las sumas de espinas de pino. Por ejemplo, dice que el paquete que reúne 18 manojos, cada uno con un número distinto de espinas $(12 \times 38+29-27-22-12-13-14)$, contiene 
573 espinas (Lipp, 1991, p. 110). El mismo autor presenta la p. 5 del Códice FejérváryMayer (ibid., Fig. 11, p. 115) que muestra tres estratos de números (10 veces 11 objetos no identificados en el estrato superior ; lo mismo en el estrato que precede, y 11 veces 10 objetos no identificados en el estrato inferior), y calcula el total del modo siguiente : $10 \times 11+10 \times 11+11 \times 11=341^{20}$.

Este análisis de las ofrendas tlapanecas es todavía demasiado limitado como para ofrecer un marco general explicativo para las of rendas mesoamericanas. Sin embargo, me parece que el papel categorizante del número debe ser un rasgo esencial del sistema. En todo caso, no se trata de numerar espinas, hojuelas o flores para llegar a sumar cientos o miles de ellos, sino de crear categorías semánticas eficaces ${ }^{21}$. En este cjemplo, los números permiten representar la deidad y, de manera secundaria, lo que se pide (la cosecha) y el periodo para el cual se pide (el Tiempo) ${ }^{22}$. La comparación debe ser proseguida para sacar a luz los modelos de ofrendas (niveles y estratos con significados distintos) y los simbolismos numéricos, que suponemos deben variar según los lugares.

* Manuscrit reçu en mars 2001, accepté pour publication en juin 2001.

\section{NOTAS}

1. Deseo expresar mi agradecimiento a Antonio González García, ex presidente del municipio de Acatepec y a las autoridades municipales y xiña de la comunidad de Apetzuca, en especial Alberto Neri Nayo, comisario, Bacilio Dircio Librado, coordinador, Emilio Lorenzo Espinoza, delegado de la palabra de Dios, Prisciliano García Flores, consejero del pueblo. Igualmente a las autoridades y xiña de Tres Cruces, en especial, Marcelino Reyes Agustino y Antonio Casimiro. Agradezco también a Rodolfo Avila Villegas, Concepción Asuar (CEMCA) y Jean-Marc Chavy (UMR 7535, Nanterre) su ayuda en la presentación de las ilustraciones $\mathrm{n}^{\circ} 4,5,6$ y 9. Las fótos (Fig. 1, 2, 3, 7 y 8) se deben a la ayuda de Jean-Dominique Bailleul (Universidad Paris VIII) y los Films du Village. Finalmente agradezco a Helios Figuerola y Guilhem Olivier unas observaciones y consejos valiosos.

2. Leonhardt Schultze Jena : Bei den Aztekan, Mixteken und Tlapaneken der sierra Madre del Sur von Mexiko, Indiana, G. Fischer, Jena, 1938, vol. 3.

3. Marion Oettinger describe un ritual en : " The Burning of the Firewood Ceremony : Final Consecration of Marriage in the Tlapanec Community of Tlacoapa, Guerrero », Balance y perspectiva de la antropologia de Mesoamérica y el norte de México, XIII Mesa Redonda de la Sociedad Mexicana de Antropología, México, 1973, pp. 195-205; y Una commidad tlapaneca, sus linderos sociales y territoriales, México, Instituto Nacional Indigenista, 1980, pp. 218-236. Peter van der Loo describe tres rituales de Malinaltepec en: "Rituales con manojos contados en el Grupo Borgia y entre los tlapanecos de hoy día ", Coloquio Internacional, Los Indigenas de México en la época prehispánica y en la actualidad, Leiden, Rutgers B. V., 1982, pp. 232-243. Códices, Costumbres, Contimuidad, un estudio de la religión mesoamericana, Leiden, Archeologisch Centrum R.U., 1987. Códice Cospi, México, Fondo de Cultura Económica, 1994, pp. 267-287.

4. Pedro Carrasco: "Pagan Rituals and Beliefs among the Chontal Indians of Oaxaca, Mexico», Anthropological Records (Berkeley) 20, 1960, pp. 87-114. Paul R. Turner : The Highland Chontal, New York, Holt, Rinehart \& Winston, 1972. Frank J. Lipp : The Mixe of Oaxaca, Religion, Ritual and Healing, Austin, University of Texas Press, 1991.

5. Provienen, según los autores, de la región de Cholula, de la Mixteca Alta o de la Costa del Golfo. Para una síntesis sobre este punto muy discutido, véase : Peter van der Loo, op. cit., 1987, pp. 28-31.

6. Karl Anton Nowotny : Tlacuilolli, Berlin, Mann, 1961.

7. El proceso de fraccionamiento de los pueblos en la historia está detallado en Danièle Dehouve: Ensajo de geopolítica indigena. Los municipios tlapanecos, México, Grupo Editorial Porrúa-CIESAS, 2001. 
8. Un artículo sobre el significado de estos rituales en la legitimación sagrada del poder político está actualmente en preparación.

9. De la abundante bibliografía dedicada al dios del Fuego señalamos unos títulos más importantes : entre los documentos originales, véanse la lámina 1 del Códice Fejérvíry-Mayer, la p. 46 del Códice Borbónico y la obra de Sahagún (Historia general de las cosas de Nueva España, L. VII, cap. X-XIII). Entre los análisis, Ferdinand Anders, Maarten Jansen, Luis Reyes García : El Libro del Ciuacoatl, Homenaje para el año del Fuego Nuevo, libro explicativo del llamado Códice Borbónico, Graz-Madrid-México, Sociedad Estatal Quinto Centenario-Akademische Druck-und Verlagsanstalt-Fondo de Cultura Económica, 1991. Leonardo López Luján : Las ofrendas del templo mayor de Tenochtitlán, México, INAH, 1993. Alfredo López Austin : «El dios enmascarado del fuego », Anales de Antropologia, XXII, 1985, pp. 251-285.

10. Johanna Broda : «Mesoamerican Astronomy and the Ritual Calendar », Helaine Selin ed., Astronomy' across Cultures, The History of Non-Western Astronomy, Dordrecht-Boston-London, Kluwer Academic Publishers, 2000, pp. 225-267.

11. La relación entre un nuevo poder político y cl sol está señalado por Guilhem Olivier : « Les paquets sacrés ou la mémoire cachée des Indiens du Mexique central (Xve-xvie siècles) », Journal de la Société des Américanistes, 81, 1995, pp. 105-141, 136, nota 45, citando a Sahagín : " Ahora alumbra el sol, es día : significa que algo nuevo aparece, un nuevo uso empieza, o el señor se asienta, está escogido ».

12. El cuadrado de leños no se realiza únicamente con finalidades rituales, sino que también sirve en la vida cotidiana para secar los leǹos verdes. Helios Figuerola (comunicación personal) ha notado la misma costumbre en Cancuc, en los Altos de Chiapas, donde, además, en una que otra ocasión, los campesinos se sirven de dicho cuadrado para encerrar de manera temporaria alguna gallina. Reconocemos aquí el papel secundario de «caja » o « corral» del cuadrado. Cabe precisar que el mismo simbolismo está compartido por otras construcciones, en particular el granero de maíz (ctezcomatl en náhuatl), en el cual se pone a salvo la cosecha.

13. El término náhuatl poton puede estar relacionado con potonia : « poner una cataplasma a alguién, emplumar a alguién ; en s. f. consolar, agraciar, ser misericordioso, liberal, dar una limosna ", Réni Siméon : Diccionario de la lengua Náhuatl, México, Siglo XXI, 1977, p. 394.

14. Según Brent Berlin, Dennis E. Breedlove and Peter H. Raven : Principles of Tzeltal Plant Classiffcation, New York and London, Academic Press, 1974. Ver el término tzeltal cilcil 'tuhc'. El significado del término tlapaneco ina es hoja.

15. En la época prehispánica y colonial, esa región pagó muchos tributos de oro y todavía se conocen « minas » en ella.

16. El significado de los números que presento aquí y a continuación ha sido proporcionado por los habitantes de los pueblos, en especial, los xiña. Lo único que añadí a su exégesis son las referencias al pasado precortesiano.

17. Véase en particular Miguel León-Portilla : La Filosofia Náluatl, México, UNAM [1956] 1993.

18. Cabe notar que 24 fue el número del Fuego en la «quema de leña » matrimonial realizada en presencia de Schultze Jena en los años treinta (Schultze Jena, op. cit., 1938, vol. 3, p. 149).

19. Los códices del Grupo Borgia y los códices mixtecos pintan muy a menudo los señores y los dioses con collares y coronas de flores : véase, por ejemplo, el personaje identificado por Alfonso Caso como un rey en el Códice Bodley 7-II (Alfonso Caso : Rejes y reinos de la Mixteca, México, Fondo de Cultura Econónica, 1977, t. I : Lámina V d). Alain Ichon señala por su parte que «On s'imagine les dieux rassemblés à l'Est autour d'une «Grande Table » couverte de ffeurs et d'aliments, et eux-mêmes bien vêtus, bien ornés de colliers et de couronnes de fleurs " (Alain Ichon : La religion des Totonaques de la Sierra, Paris, éd. du CNRS, 1969, p. 142).

20. Seler había tratado de hacer lo mismo, buscando números con significado astronómico, sin éxito. Por esa razón, había sido criticado por Nowotny y Peter van der Loo (1987).

21. Alain Ichon llega a conclusiones semejantes a propósito de los totonacos : «Il semble donc que les munecos de bois totonaques correspondent aux figurines de papier tepehuas [...] et otomies, le symbolisme mumérique remplaçant pour désigner les dieux, celui de la forme et de la couleur. Mais ce symbolisme est limité aux nombres symboliques eux-mêmes : 4, 7 et 17, 12 et 13,20,25, et multiples de 25 ; alors que les combinaisons permises par les papiers découpés sont illimitées. Aussi assiste-t-on chez les Tepehuas à une évolution qui tend de plus en plus à éloigner la figurine de ce qu'elle était à l'origine et de ce qu'elle est restée chez les Totonaques : une représentation de la divinité » (Ichon, op. cit., p. 235).

22. El tema se presta para la comparación antropológica, y cabe señalar la interpretación proporcionada por el Veda hindú de la construcción del Fuego con 24 ladrillos (Charles Malamoud : «Briques et mots », 
Corps des dieux, sous la direction de Charles Malamoud et Jean-Pierre Vernant, Paris, Gallimard, Le Temps de la Réflexion, 1986, pp. 77-98).

\section{BIBLIOGRAFÍA}

ANDERS, Ferdinand, JANSEN, Maarten y Luis REYES GARCIA, 1991. - El Libro del Ciuacoatl, Homenaje para el año del Fuego Nuevo, libro explicativo del llamado Códice Borbónico, Sociedad Estatal Quinto Centenario-Akademische Druck-und Verlagsanstalt-Fondo de Cultura Económica, Graz-Madrid-México.

-, 1992. - Origen e Historia de los Reyes Mixtecos, Libro explicativo del llamado Códice Vindobonensis, Sociedad Estatal Quinto Centenario-Akademische Druck-und Verlagsanstalt-Fondo de Cultura Económica, Graz-Madrid-México.

Berlin, Brent, Breedlove, Dennis E. and Peter H. Raven, 1974. - Principles of Tzeltal Plant Classification, Academic Press, New York and London.

BroDA, Johanna, 2000. - « Mesoamerican Astronomy and the Ritual Calendar 》, in : Helaine Selin, (ed.), Astronomy across Cultures, The History of Non-Western Astronomy, Kluwer Academic Publishers, Dordrecht-Boston-London, pp. 225-267.

Carrasco, Pedro, 1960. - « Pagan Rituals and Beliefs among the Chontal Indians of Oaxaca, Mexico », Anthropological Records (Berkeley) 20, pp. 87-114.

Caso, Alfonso, 1977. - Reyes y reinos de la Mixteca, Fondo de Cultura Económica, México, $2 \mathrm{t}$.

Catedral, 1953, revista de la Diócesis de Chilapa.

Códice Borbónico, 1974, edición facsimilar, ADEVA, Graz; nueva ed. Fondo de Cultura Económica, México, 1991.

Códice Borgia, 1963, Fondo de Cultura Económica, México-Buenos Aires, 3 t. ; nueva ed., ADEVA, Graz, 1976.

Códice Cospi, 1968, edición facsimilar, ADEVA, Graz ; nueva ed., Fondo de Cultura Económica, México, 1994.

Códice Fejéruáry-Mayer, 1971, edición facsimilar, ADEVA, Graz.

Códice Laud, 1966, edición facsimilar, ADEVA, Graz.

Códice Vindobonensis, 1963, edición facsimilar, ADEVA, Graz; nueva ed., Fondo de Cultura Económica, México, 1992.

DeHouve, Danièle, 2001. - Ensayo de geopolitica indlgena. Los municipios tlapanecos, Grupo Editorial Porrúa-CIESAS-CEMCA, México.

IcHoN, Alain, 1969. — La religion des Totonaques de la Sierra, éd. du CNRS, Paris.

León-Portilla, Miguel, [1956] 1993. — La Filosofia Náhuatl, UNAM, México.

LIPP, Frank J., 1991. 一 The Mixe of Oaxaca, Religion, Ritual and Healing, University of Texas Press, Austin.

LóPEz Austin, Alfredo, 1985. - «El dios enmascarado del fuego », Anales de Antropología, XXII, pp. 251-285.

LópEZ LuJÁN, Leonardo, 1993. — Las ofrendas del templo mayor de Tenochtitlán, INAH, México. 
Malamoud, Charles, 1986. — «Briques et mots ", in : Corps des dieux, sous la direction de Charles Malamoud et Jean-Pierre Vernant, Gallimard, Le Temps de la Réflexion, Paris, pp. 77-98.

Nowotny, Karl Anton, 1961. - Tlacuilolli, Mann, Berlin.

OetTiNGER, Marion, 1973. - « The Burning of the Firewood Ceremony : Final Consecration of Marriage in the Tlapanec Community of Tlacoapa, Guerrero ", Balance y perspectiva de la antropología de Mesoamérica y el norte de México, XIII Mesa Redonda de la Sociedad Mexicana de Antropología, México, pp. 195-205.

—, 1980. - Una comunidad tlapaneca, sus linderos sociales y territoriales, Instituto Nacional Indigenista, México.

OLIvieR, Guilhem, 1995. - « Les paquets sacrés ou la mémoire cachée des Indiens du Mexique central, $\mathrm{XV}^{e}-\mathrm{XVI}^{\mathrm{e}}$ siècles ", Journal de la Société des Américanistes, 81, pp. 105-141.

RuIZ DR ALARcón, Hernando, [1629] 1892. - Tratado de las supersticiones y costumbres gentilicas que oy viuen entre los indios naturales desta Nueva España, Imprenta del Museo Nacional, México.

SAHAGún, Bernardino de, 1985. - Historia general de las cosas de Nueva España, ed. Porrúa, México.

Schultze Jena, Leonhardt, 1938. - « Bei den Aztekan, Mixteken und Tlapaneken der sierra Madre del Sur von Mexiko », Indiana, G. Fischer, Jena, vol. 3.

Siméon, Rémi, 1977. - Diccionario de la lengua Náhuatl, Sigło XXI, México.

Turner, Paul R., 1972. - The Highland Chontal, Holt, Rinehart \& Winston, New York.

VAN DER LOO, Peter, 1982. — « Rituales con manojos contados en el Grupo Borgia y entre los Tlapanecos de hoy día ", Coloquio Internacional, Los Indigenas de México en la época prehispánica y en la actualidad, Rutgers B. V., Leiden, pp. 232-243.

-, 1987. - Códices, Costumbres, Continuidad, un estudio de la religión mesoamericana, Archeologisch Centrum R.U., Leiden. 